\title{
BENJAMIN E ADORNO: UM DEBATE SOBRE A ARTE NO SÉCULO XX
}

\author{
Wesley Carlos de Abreu $^{1}$
}

\begin{abstract}
RESUMO
O artigo pretende realizar um debate sobre o pensamento estético de Benjamin e Adorno sobre a arte no século $X X$ e relacionar esse debate na convergência de teorias que os filósofos desenvolveram em seus textos. Esta divergência acontece na leitura dos textos que tratam da reprodutibilidade técnica da arte e da mercantilização da arte feita pela indústria cultural no capitalismo tardio. Analisaremos a concordância dos filósofos ao tratar sobre 0 movimento do Surrealismo desvinculado de interpretações psicológicas, para poder apontar o caráter negativo de Adorno e o fascínio de Benjamin sobre o papel da arte como advento da reprodutibilidade técnica ou um processo de desartização (Entkunstung). Palavras-Chave: Benjamin. Adorno. Reprodutibilidade Técnica. Surrealismo. Desartização.

\section{ABSTRACT}

This paper intends to hold a debate on the aesthetic thought of Benjamin and Adorno on art in the twentieth century and relate this debate on convergence of theories that philosophers have developed in their texts. This discrepancy occurs in reading the texts that deal with the technical reproduction of art and commodification of art made by the cultural industry in late capitalism. Then we analyze the correlation of philosophers to deal with on the movement of Surrealism Unbound psychological interpretations. And so, being able to point the negative character of Adorno and Benjamin fascination about the role of art as advent of technical reproduction or process Entkunstung.
\end{abstract}

Key-words: Benjamin. Adorno. Technical reproducibility. Surrealism. Entkunstung.

O debate sobre a arte entre Walter Benjamin e Theodor W. Adorno no século XX pode ser caracterizado num diálogo propriamente de aceitação e refutação que ambos propõem sobre a essência da arte como um novo advento do mundo extremamente tecnológico e digital, considerando os últimos trinta anos. Esse debate oferece um riquíssimo campo de teorias sobre a obra de arte.

Benjamin e Adorno divergem em pontos importantes, principalmente nos conceitos que elaboram para refletir sobre a arte. Benjamin usa o famoso conceito de "reprodutibilidade técnica" no texto "A obra de arte na era de sua reprodutibilidade técnica", para analisar a transformação que as novas formas de reprodução

\footnotetext{
1 Wesley Carlos de Abreu é Mestrando do Curso de Pós-Graduação em Filosofia da Universidade Federal do Ceará (UFC).
} 
alteraram a forma de contato que as pessoas tem com a obra de arte e também a maneira como os artistas realizam sua criação. Anos depois, Adorno, influenciado pela leitura do ensaio de Benjamin, escreve "A indústria cultural: o esclarecimento como mistificação das massas" como um capítulo pertencente à Dialética do Esclarecimento $^{2}$. Neste texto, Adorno traça o perfil na qual a cultura se transformou em instrumento da dominação do sistema e a arte em mercadoria estandartizada, considerando, contudo que a reprodutibilidade técnica analisada por Benjamin, apesar de ter modificado a obra de arte, tornando-a livre de um substrato único, ao mesmo tempo, a partir de Adorno, tal época da reprodução técnica não conseguiu emancipar a arte de seu caráter aurático. Assim, Buscaremos compreender a respeito da hipótese de que a arte, após este processo de desrautização já exposta por Benjamin, passa, na análise de Adorno, por um processo de desartização.

\section{Indústria Cultural e Reprodutibilidade Técnica}

O mundo atual é consequência da revolução burguesa que não se parece em nada com o que a precedeu, nem semelhante, nem honesta, nem aberta à verdade. O que a revolução burguesa nos trouxe foi um mundo do capitalismo que sufoca e progride sem ver as consequências devastadoras de suas ambições no âmbito da economia, do comércio e do social. Podemos, então, incluir também, nas mãos desse domínio, o campo da arte? Benjamin e Adorno nos levam a caminhos de reflexão que dão luzes a esta resposta, porém o debate divergente dos dois nos leva, de certa maneira, a fazer uma escolha da melhor teoria para retratar o estado e o papel que arte tem em nosso tempo.

O mundo da arte apresenta uma convergência que vai apontar todos os debates no campo da cultura, a ascensão das vanguardas e dos meios de reprodutibilidade técnica que dão base ao mercado de consumidores massivos por produtos culturais. O perfil tomado pelos meios de reprodutibilidade técnica, ou seja, seu cumprimento às leis do mercado, e dessa forma, sua entrada na lógica capitalista posicionada na ligação entre práxis e ideologia, fundam a crítica de Adorno à indústria cultural, pois ela transforma tudo em semelhança, por razão do retorno lucrativo dos negócios. A estrutura esquemática e repetitiva é de imediato reconhecimento pelas pessoas e insere a obra de arte na previsibilidade e, assim no fácil reconhecimento. Está é a fórmula do sucesso.

\footnotetext{
2 Obra foi escrita em parceria com Max Horkheimer.
} 
Desde o começo do filme já se sabe como ele termina, quem é recompensado, e, ao escutar a música ligeira, o ouvido treinado é perfeitamente capaz, desde os primeiros compassos, de adivinhar o desenvolvimento do tema e sente-se feliz quando ele tem lugar como previsto. $^{3}$

A falta do "novo" nos produtos culturais desaparece sem que se note pelo público, pois a novidade tecnológica distrai com seu efeito especial. Assim, a indústria cultural reduz "os elementos inconciliáveis da cultura, arte e divertimento", a "um falso denominador comum". Logo, a adaptação dos meios técnicos para o consumo de massa assume as regras do próprio capitalismo criticado por Adorno no capítulo sobre a indústria cultural da Dialética do Esclarecimento. A obra de arte é agora uma mercadoria que tem o papel de chamar a atenção de uma quantidade de consumidores para sua diversão. Na verdade esse entretenimento passa a ser um "prolongamento do trabalho sob o capitalismo tardio".

A lógica é simples: o proveito do sistema capitalista, o procedimento repetitivo do esquema na linha de produção de trabalho, diminui a livre ação e autonomia e o potencial de criação do indivíduo. O produto da indústria cultural dispõe a maneira do entreter como uma "distração" da opressão que leva com ela uma promessa de salvação e uma percepção ideológica da realidade de que, a qualquer instante, o indivíduo será agraciado pelo sistema (como ser sorteado para uma casa na promoção de uma loja, ou ganhar na loteria, e ainda tornar-se uma celebridade ao vencer um reality show da tv.), espalhando assim modelos de comportamento e desejos que serão continuamente alimentados pela indústria cultural.

Adorno escreve que a pergunta: "Mas o que é que as pessoas querem?, consiste em se dirigir às pessoas como sujeitos pensantes, quando sua missão especifica é desacostumá-las da subjetividade". A indústria cultural é a maneira pela qual o capitalismo domina o tempo livre ${ }^{6}$ do sujeito e sua capacidade de fazer escolhas, ou seja, de ser sujeito. Adorno indica para a insustentabilidade de uma renovação pensada nos termos marxistas, pois os movimentos de contestação, motivados pela exploração de domínio, foram neutralizados por uma promessa que não se concretiza no âmbito coletivo, mas que fica na vontade individual de um

3 ADORNO, HORKHEIMER. Dialética do Esclarecimento: fragmentos filosóficos. Rio de Janeiro: Jorge Zahar Ed., 2006, p. 103.

4 ADORNO. 2006, p.112.

5 ADORNO. 2006, p. 113.

6 . Tempo Livre. In: Palavras e Sinais: modelos críticos 2. Trad. bras. Maria Helena Ruschel. Petrópolis: Vozes, 1995, p. $70-82$. 
indivíduo que percebe a realidade em volta, e cuja vontade até foi previamente programada pela esquema:

$\mathrm{Na}$ era da estatística, as massas estão muito escaldadas para se identificar com o milionário na tela. (...) A felicidade não deve chegar para todos, mas para quem tira a sorte, ou melhor para quem é designado por uma potência superior - na maioria das vezes a própria indústria do prazer, que é incessantemente apresentada como estando em busca dessa pessoa. (...) A starlet deve simbolizar a empregada de escritório, mas de tal sorte que, diferentemente da verdadeira, o grande vestido de noite já parece talhado para ela. ${ }^{7}$

Não há movimento de revolução porque todos aguardam a mesma redenção e permanecem sob o sinal da concordância:

Mas a afinidade original entre os negócios e a diversão mostra-se em seu próprio sentido: a apologia da sociedade. Divertir-se significa estar de acordo. (...) Divertir-se significa sempre: não ter que pensar nisso, esquecer o sofrimento até mesmo onde ele é mostrado. A impotência é a sua própria base. É a verdade uma fuga, mas não, como afirma, uma fuga da realidade ruim, mas da última ideia de resistência que essa afirma, uma fuga da realidade ainda deixa subsistir. ${ }^{8}$

Numa observação mais geral da Dialética do Esclarecimento, a superação da razão técnica sobre a razão autônoma demonstra a glória das ideologias totalitárias e fascistas mesmo em estados essencialmente democráticos.

Devemos compreender que a estandartização ${ }^{9}$ da arte pela indústria cultural e sua técnica só realizou a produção em série. Tomando ciência disso, pode haver muitos erros na leitura do texto de Adorno. Isso porque a tecnologia ficou diretamente ligada à banalização do discurso, uma vez que, como observa o próprio filósofo, a contínua exploração do "novo" utilizada como entretenimento expõe a repetição vazia da mesma estrutura ideológica, além da proximidade que a expressão "razão técnica" pode ter com a tecnologia.

Assim, o texto de Adorno sobre a indústria cultural na Dialética do Esclarecimento, se aproxima muito do texto "A obra de arte na era de sua reprodutibilidade técnica" de Walter Benjamin, ensaio escrito onze antes da publicação da Dialética do Esclarecimento. Esse texto de Benjamin também apontou

\footnotetext{
7 ADORNO, HORKHEIMER. Dialética do Esclarecimento: fragmentos filosóficos. Rio de Janeiro: Jorge Zahar Ed., 2006, p. 120

8 Idem, p. 119.

9 ADORNO. A indústria cultural. In: COHN, Gabriel (org.). Sociologia. São Paulo: Ática, 1994, p. 92 99.
} 
a dominação dos meios de reprodutibilidade pela exploração do sistema ideológico capitalista $^{10}$.

Mas, certamente o que atrai nossa observação no ensaio de Benjamin é a tese da perda da aura da obra de arte com o surgimento dos meios de produção técnica, ao assinalar que esses meios mudaram o conceito de arte. Esse pensamento de Benjamin transformou seu ensaio em um modelo teórico fundamental para o entendimento das direções que a arte seguiria a partir de então.

A mudança do conceito de arte e a perda da aura são interdependentes, pois diz Benjamin, "o conceito de aura permite resumir essas características: o que se atrofia na era da reprodutibilidade técnica da obra de arte é a sua aura" ${ }^{\prime 1}$. Parte do texto de Benjamin é motivado à compreensão do conceito. Não se pode compreender a aura como um aspecto concreto da obra simplesmente. Benjamin não quer dizer isso. Mesmo que a aura se fundamente na ideia de unicidade e autenticidade, sua característica física é só um lado do fenômeno. O que foge à reprodutibilidade técnica é que ela não conseguiu extrair da obra de arte a existência única, "o aqui e agora da obra de arte" em que se desdobra toda sua história.

Esse fenômeno representa, além de todas as transformações que a obra de arte recebeu durante os tempos, as relações de propriedade em que ela esteve, como objeto de culto (Kultwert) - resquícios de uma tradição que nasce do lugar o do motivo pelo qual a obra original foi criada. Isto é o que escapa a reprodutibilidade técnica. A técnica de reprodução retira da obra original esse valor, mesmo que a obra de arte reproduzida esteja livre e podendo estar em qualquer lugar e tempo. Assim, a aura não é um aspecto físico da obra, porém seu revestimento simbólico: sua unicidade caracteriza também a experiência única do sujeito diante da obra. Experiência que está baseada no que Benjamin denominou como "valor de culto".

A forma mais primitiva de inserção da arte no contexto da tradição se exprimia no culto. As mais antigas obras de arte, como sabemos, surgiram a serviço de um ritual, inicialmente mágico, depois religioso. O que é de

\footnotetext{
${ }^{10}$ Logo no inicio de seu ensaio Benjamin trata um pouca da superestrutura da qual Marx falou sobre o sistema capitalista: "Marx empreendeu a análise do modo de produção capitalista, esse modo de produção ainda estava em seus primórdios. Marx orientou sua investigações de forma a dar-lhes valor de prognósticos. Remontou às relações fundamentais de produção capitalista e, ao descrevêlas, previu o futuro do capitalismo. Concluiu que se podia esperar desse sistema não somente uma exploração crescente do proletariado, mas também, em última análise, a criação de condições para a sua própria supressão" (BENJAMIN, Walter. A obra de arte na era de sua reprodutibilidade técnica. In: Obras Escolhidas. Magia e Técnica, Arte e Politica. Trad. Br. Sérgio. P. Rouanet. São Paulo: Brasiliense, 1994, p. 167).

11 BENJAMIN. 1994, p. 168.
} 
importância decisiva é que esse modo de ser aurático da obra de arte nunca se destaca completamente de sua função ritual. Em outras palavras: o valor único da obra de arte tem sempre um fundamento teológico, por mais remoto que seja. ${ }^{12}$

Isso demonstra que a aura se mostra uma espécie de ligação entre público e obra dentro da tradição e na contemplação distante. E foi essa ligação que foi completamente mudada, pois, para Benjamin, a reprodutibilidade técnica emancipa a obra de arte, "pela primeira vez na história, de sua existência parasitária, destacando-a do ritual ${ }^{13}$. Assim, com a obra de arte liberta de sua função ritual o valor de culto é posto para trás pelo "valor de exposição"(Ausstellungswert) surgido com a reprodutibilidade técnica que traz para perto tudo que arte tinha como distante:

Fazer as coisas ficarem mais próximas é uma preocupação tão apaixonada das massas modernas como sua tendência a superar o caráter único de todos os fatos através de sua reprodutibilidade. Cada dia fica mais irresistível a necessidade de possuir o objeto, de tão perto quanto possível, na imagem, ou antes, na sua cópia, na sua reprodução. ${ }^{14}$

Benjamin diz existirem dois caminhos: por um lado, a apropriação dos meios pelo capitalismo que esvazia sua possibilidade revolucionária; por outro, a introdução das técnicas como fator que modifica a experiência e o modo de perceber. A arte assume nova função: "no momento em que o critério da autenticidade deixa de aplicar-se à produção artística, toda a função da arte se transforma. Em vez de fundar-se no ritual, ela passa a fundar-se em outra práxis: a política" ${ }^{\prime 15}$.

E não há lugar mais para nenhuma nostalgia do passado pois "a arte contemporânea será tanto mais eficaz quanto mais se orientar em função da reprodutibilidade e, portanto, quanto menos colocar em seu centro a obra original" ${ }^{\text {"16. }}$. O valor da arte não está na espécie de experiência que ela considera, se contemplativa, próxima ou distante, porém, na experiência que traga novas percepções ao sujeito. Para Benjamin, é um tipo de privilégio de nosso tempo, na história humana, pois nunca houve antes uma técnica que concedesse tantas possibilidades.

\footnotetext{
12 BENJAMIN. A obra de arte na era de sua reprodutibilidade técnica. In: Obras Escolhidas. Magia e Técnica, Arte e Politica. Trad. Br. Sérgio. P. Rouanet. São Paulo: Brasiliense, 1994, p.171.

${ }^{13}$ BENJAMIN. 1994, p. 171.

14 Idem. p.170.

${ }^{15}$ BENJAMIN. 1994, p. 171-172.

${ }^{16}$ BENJAMIN. 1994, p. 180.
} 
Mas essa técnica emancipada se confronta com a sociedade moderna sob a forma de uma segunda natureza, não menos elementar que a da sociedade primitiva, como provam as guerras e as crises econômicas. Diante dessa segunda natureza, que o homem inventou mas há muito não controla, somos obrigados a aprender, como outrora diante da primeira. Mais uma vez, a arte põe-se a serviço desse aprendizado. Isso se aplica em primeira instância ao cinema. O filme serve para exercitar o homem nas novas percepções e reações exigidas por um aparelho técnico cujo papel cresce cada vez mais em sua vida cotidiana. Fazer do gigantesco aparelho técnico do nosso tempo o objeto das inervações humanas - é essa a tarefa histórica cuja realização dá ao cinema o seu verdadeiro sentido. ${ }^{17}$

Temos assim, um primeiro momento ate aqui do debate entre Benjamin e Adorno ao falarmos de indústria cultural e reprodutibilidade técnica. Claramente o texto de Adorno é um reflexo crítico do atual estado da arte naquele período, e ele, após ler o ensaio sobre a reprodutibilidade técnica de Benjamin, fomentou mais sua posição frente a arte estandartizada que toma a autonomia e o potencial de contemplação do sujeito. Um exemplo que ele usa é a abordagem da função do cinema:

O mundo inteiro é forçado a passar pelo filtro da indústria cultural. [...] quanto maior a perfeição com que suas técnicas duplicam os objetos empíricos, mais fácil se torna hoje obter a ilusão de que o mundo exterior é o prolongamento sem ruptura do mundo que se descobre no filme. [...] o filme adestra o espectador entregue a ele para se identificar imediatamente com a realidade. Atualmente a atrofia da imaginação e da espontaneidade do consumidor cultural não precisa ser reduzida a mecanismos psicológicos. Os próprios produtos - entre eles em primeiro lugar o mais característico, o filme sonoro - paralisam essas capacidades em virtude de sua própria constituição objetiva. São efeitos de tal forma que sua apreensão adequada exige, é verdade, presteza, dom de observação, conhecimentos específicos, mas também de tal sorte que proíbem a atividade intelectual do espectador, se ele não quiser perder os fatos que desfilam velozmente diante de seus olhos. ${ }^{18}$

Com um argumento semelhante argumento, Benjamin também discute sobre o papel do cinema:

Através da distração, como ela nos é oferecida pela arte, podemos avaliar,
indiretamente, até que ponto nossa percepção está apta a responder a
novas tarefas. (...), a arte conseguirá receber as mais difíceis e importantes
sempre que possa mobilizar as massas. É o que ela faz, hoje em dia, no
cinema. A recepção através da distração, que se observa crescentemente
em todas os domínios da arte e constitui o sintoma de transformação
profunda nas estruturas perceptivas, tem no cinema o seu cenário
privilegiado. E aqui, onde a coletividade procura a distração, não falta de
modo algum a dominante tátil, que rege a reestruturação do sistema
perceptivo. É na arquitetura que ela está em seu elemento, de forma mais

${ }^{17}$ Idem. p. 174

${ }^{18}$ ADORNO, HORKHEIMER. Dialética do Esclarecimento: fragmentos filosóficos. Rio de Janeiro: Jorge Zahar Ed., 2006, p. 104. 
originária. Mas nada revela mais claramente as violentas tensões do nosso tempo que $\mathrm{p}$ fato de que essa dominante tátil prevalece no próprio universo da ótica. É justamente o que acontece no cinema, através do efeito de choque de suas sequências de imagens. ${ }^{19}$

\section{Negatividade e Fascínio sobre a arte}

A reflexão dissonante entre Benjamin e Adorno sobre a perda da aura se verifica no fim da autenticidade e unicidade da obra de arte. Contudo, em Adorno esta realidade recebe um negativismo, fruto da reprodutibilidade técnica e dos processos de democratização e massificação da arte. Adorno pensa, por exemplo, que a reprodução em série do quadro de Mona Lisa, será consequência da reprodução técnica que retira da obra sua essência. Com isso nasce a "dissolução na realidade banal, através da indústria cultural e, portanto, a destruição do valor de negatividade inerente à arte e à despolitização do seu destinatário"20.

Sobre os processos de democratização e massificação da arte, esta envolve em Adorno ${ }^{21}$ a separação dos elementos constituintes da obra de arte e, com ela, acontece a perda da dimensão crítica da arte, ou seja, o fim de sua representação histórica para as gerações. Adorno é defensor da arte preservada em sua total constituição e não dissolvida em processos de reprodução e serialização, Adorno defende, portanto, que o modo de preservar a existência da consciência crítica da arte deve acontecer na arte aurática.

Para Benjamin a obra de arte tem outro papel. Para ele, como já sabemos, a destruição da autenticidade e unicidade da obra de arte leva à perda do valor de culto, porém intensifica seu "valor de exposição". Assim, o objeto artístico se torna acessível a todos; esse acesso generalizado se torna possível e a obra adquire um novo valor atrelado: o valor de consumo. Para o filósofo, a reprodução em série do quadro da Mona Lisa, digamos em uma estampa de camiseta, ou a capa de um CD de uma banda de Rock, não descaracteriza a obra de arte, apenas a retira do seu lugar permanente em museus e galerias de artes, para ser mostrada e admirada por todos.

${ }^{19}$ BENJAMIN. A obra de arte na era de sua reprodutibilidade técnica. In: Obras Escolhidas. Magia e Técnica, Arte e Politica. Trad. Br. Sérgio. P. Rouanet. São Paulo: Brasiliense, 1994, p.194.

${ }^{20}$ Freitag. 1986, p. 76.

${ }^{21} \mathrm{Na}$ Teoria Estética, Adorno apresenta uma figura sombria do que a arte se tornou em nossos dias. A uniformização da indústria cultural permitiu "a supressão da diferença entre o artista como sujeito estético e o artista como pessoa empírica" (Adorno, p. 283) e implicou que "a distância da obra de arte à empiria foi suprimida sem que, no entanto, a arte tenha sido restituída à vida livre que não existe. A sua proximidade intensifica o lucro, a imediaticidade é organizada para enganar"(Adorno, p. 283). 
Observando por esse panorama, a reprodutibilidade técnica não somente garante as compras massivas, como modifica também a característica imanente da obra de arte e permite uma mudança na própria percepção do consumidor. Com isso, as artes como a fotografia e o cinema, são exemplos singulares dessa transformação na ideia e modo de ver a arte sem a aura, pois ao causar transformações na sensibilidade perceptível e nas ações dos consumidores, servem como mecanismo de politização. Benjamin, entretanto, permanece com ceticismo, diante da arte como instrumento de modificação, mas não nega sua possibilidade:

\begin{abstract}
Não se deve, evidentemente, esquecer que a utilização política desse controle terá que esperar até que o cinema se liberte da sua exploração pelo capital. Pois o capital cinematográfico dá um caráter contrarevolucionário às oportunidades revolucionárias imanentes a esse controle. Esse capital estimula o culto do estrelado, que não visa conservar apenas a magia da personalidade, há muito reduzida ao clarão putrefato que emana de seu caráter de mercadoria, mas também o seu complemento, o culto do público, e estimula, além disso, a consciência corrupta da massas, que o fascismo tenta por no lugar de sua consciência de classe. ${ }^{22}$
\end{abstract}

Não é difícil pensar a respeito do fascínio de Benjamin, e a negatividade de Adorno, em torno da arte. Para o primeiro ela seria tão mais perfeita quanto maiores fossem as possibilidades de reprodutibilidade técnica que oferecesse. Para Adorno, pelo contrário, a arte é algo que se sonha e que se busca, e nesse sentido é um objeto raro e de uma delicadeza diáfana, como se possuísse asas translúcidas e por isso constantemente estivesse a escapar. Adorno é tão vago nos seus textos de estética, que poderíamos dizer que para ele talvez nem sequer exista arte, só a ideia, de uma aparição, como no efeito do brilho dos fogos de artifício, rápido e efêmero.

Ainda na discursão convergente entre os dois filósofos é interessante mostrar a análise do trabalho de Flávio R. Kothe ${ }^{23}$ sobre a questão da arte. Basicamente o que Kothe descobre entre Benjamin e Adorno é o fato de que, para Benjamin as possibilidades abertas pela reprodutibilidade técnica geram a retirada do sagrado da arte e com isso surgem causas positivas. Esse fenômeno, para o primeiro é uma evolução e para o segundo um retardo irreparável.

\footnotetext{
22 BENJAMIN. A obra de arte na era de sua reprodutibilidade técnica. In: Obras Escolhidas. Magia e Técnica, Arte e Politica. Trad. Br. Sérgio. P. Rouanet. São Paulo: Brasiliense, 1994, p. 180.

${ }^{23}$ KOTHE. Benjamin e Adorno: confrontos. São Paulo: Ática, 1978.
} 
Verifica-se também no desenrolar do texto de Kothe a sua ligação maior com o pensamento benjaminiano quando discute o debate dos dois filósofos sobre a arte. Kothe destaca:

\begin{abstract}
Se, noutro momento, Benjamin diz que "por próxima que esteja, obra de arte é distância, e se este "algo distanciado" é sabotado pela reprodutibilidade técnica, isto é, se a aura é destruída, ou arruinada, então a própria natureza da arte é colocada em questão. Torna-se portanto, questionável a divisão da arte proposta por Adorno, em arte com aura e arte sem aura: dificilmente ainda poderia falar em arte no caso da "arte" sem aura. Cabe, porém, destacar a assertiva de Benjamin: "Em princípio, a obra de arte sempre foi improdutível". Com isto ele não nega a sua tese básica. Ocorre que, com o desenvolvimento tecnológico, o aumento quantitativo da (possibilidade de) reprodução técnica acarretou, hegelianamente, um salto qualitativo. ${ }^{24}$
\end{abstract}

Em outra questão envolvendo o posicionamento dos dois autores sobre a "autonomia da arte", Kothe destaca que Benjamin busca encontrar a possível abertura de novas possibilidades pelo desenvolvimento tecnológico da reprodução técnica, Adorno olha essas características de modo negativo.

Adorno enfatiza um aspecto social também apontado por Benjamin: o estado de dispersão do ouvinte ou espectador moderno. Quando a música passa a funcionar quase só como fundo musical, ela já não é mais percebida como um todo em si - sua autonomia é destruída. Isso representa uma regressão do ato de ouvir. E quando o "homem da massa" ouve, ouve porque todos os mecanismos de reprodução e depressão social o obrigam a conhecer certas cançonetas para ele ser aceito socialmente. $O$ valor de troca se sobrepõe ao valor de uso e o substitui: o fetichismo se instaura na arte. Isso é acompanhado por uma regressão do público, pois há um fechamento deste consumidor em relação aos novos níveis alcançados pela própria arte. Sair deste impasse - em vez de quase emperrar nele, absolutizando (como o fez Adorno) - é o que Benjamin e Brecht procuraram fazer. ${ }^{25}$

Enfim, quando procura mostrar o caráter da arte como meio crítico para a desalienação da estrutura da realidade social entre Benjamin e Adorno, Kothe escreve:

Benjamin e Brecht, na linha do docere horaciano, pregaram a necessidade da arte influenciar nas consciências e auxiliar na modificação das relações sociais, sem que, com isso, pretendessem retornar à magia, e muito menos, reforçar o caráter aurático da arte. Antes, pelo contrário, através da adoção e aplicação das novas técnicas a própria técnica da obra, destruindo a aura, mostrando que não era como feitiços que se minorariam os males sociais, e que procuraram influenciar na sociedade em que viveram. Desmistificando a arte, desmistificaram o social; desmistificando o social pela arte e pela crítica literária, crivam novas possibilidades de arte e novos níveis de crítica. Adorno, com seu artista-guardião-da-utopia-improferível e com sua arte-

\footnotetext{
${ }^{24}$ Idem, p.36)

25 Idem, p. 49-50
} 
indicadora-duma-práxis-melhor, acaba em uma utopia radical, mas vazia e inócua, e em uma práxis artística sem qualquer mediação com a práxis real - ele, que sempre tanto pregou a necessidade de "mediação", até do imediato. $^{26}$

\section{Um ponto de conciliação: o Surrealismo}

A sublevação do Surrealismo no mundo da arte e sua visão sobre a realidade é, geralmente, ligada ao escape da racionalidade. Quando o movimento procura retratar artisticamente 0 inconsciente, a proposta do Surrealismo estaria arquitetando uma via para expressar o poder da libertação. A reação crítica desse trabalho artístico redundaria na aversão à razão e na preferência pelos instintos e impulsos oprimidos na sociedade. Tanto Benjamin quanto Adorno estão de acordo em negar que o interesse do Surrealismo se encontra totalmente inserido no inconsciente.

No texto "Revendo o Surrealismo", Adorno procura desvincular essa escola artística do século $X X$ da psicanálise, revelando como a maneira artística preferida pelos surrealistas não é suficientemente capaz de retratar as imagens que surgem nos sonhos. Isso porque a consciência do artista no instante da elaboração-criação da obra não deixa o livre fluxo de imagens, pois as imagens do sonho só podem ocorrer no inconsciente, ficando uma reprodução não fiel do sonho. $O$ artista, para "reproduzir" essa liberdade de associação, tem que se esforçar para se auto extinguir. Esse esforço de auto extinção do eu-consciente, necessário ao artista com pretensões surrealistas, não ocorre no sonho. Essa consciência involuntária do artista no ato criativo e o elemento que confere ao Surrealismo uma certa objetividade,não acontece no sonho, onde a consciência está ausente desde o princípio.

Esse rigor de auto extinção do sujeito, ligado à criação artística surrealista, não permite uma observação desse movimento através do campo da Psicologia. Não colocar os surrealistas sobre análise, é uma sugestão de Adorno quando diz que ".se alguém quiser superar (aufheben) conceitualmente o Surrealismo, deve retomar não a psicologia, mas os procedimentos artísticos" ${ }^{27}$. Para Adorno, é a montagem que faz a criação artística própria do Surrealismo. Com essa montagem os surrealistas podem realizar as imagens desconcertantes e inusitadas, que tem a

\footnotetext{
${ }^{26}$ Idem, p. 52.

27 ADORNO. 2003, p. 137.
} 
força de acionar a nossa memória de uma infância deixada para trás. O potencial crítico do surrealismo estaria, para Adorno, na capacidade do inusitado de remeter

por meio do espanto, a algo familiar, aquele 'onde e que eu já vi isso tudo? A afinidade com a psicanálise não será encontrada no simbolismo do inconsciente, mas sim na tentativa de trazer a tona, por meio de explosões, as expectativas infantis. $O$ que o Surrealismo adiciona à reprodução do mundo das coisas e justamente o que perdemos de nossa infância ${ }^{28}$

O inusitado e as comparações por ele acordar seriam, então, o mecanismo com o qual o Surrealismo inventa um lugar de independência no mundo administrado, com o emprego da montagem. Assim, "as imagens dialéticas do Surrealismo são as de uma dialética da liberdade subjetiva em uma situação de nãoliberdade objetiva"29.

Em Benjamin, a intenção do movimento Surrealista segue esse mesmo teor subversivo, no sentido de "mobilizar para a revolução as energias da embriaguez" ${ }^{30}$. O filósofo lança o conceito de "iluminação profana" para observar o ideal surrealista, tendo com interesse as possibilidades de entregar a luz para o entendimento perceptivo que potencialize a compreensão da realidade alienada. Com esse conceito, Benjamin se distancia das analises que estudam o cerne mágico ou psicológico das obras de arte surrealistas.

A "iluminação profana" é importante, porque, ao mesmo tempo que repele interpretações místicas, psicológicas ou românticas, da um sentido histórico e crítico ao Surrealismo:

De nada nos serve a tentativa patética ou fantástica de apontar no enigmático o seu lado enigmático se devassamos o mistério na medida em que o encontramos no cotidiano, graças a uma ética dialética que vê o cotidiano como impenetrável e o impenetrável como cotidiano. ${ }^{31}$

As duas análises propostas por Benjamin e Adorno sobre o Surrealismo, concordam em resumo, ao ver esse movimento artístico não como um lugar tendente para conteúdos psicológicos, mas como uma possibilidade radical para voltar ao encantamento do mudo, por um lado, Adorno e a volta a infância, e do outro lado, Benjamin e sua "iluminação profana". A duas reflexões buscam uma

\footnotetext{
28 ADORNO. Revendo o Surrealismo. In: Notas de literatura I, São Paulo: Editora 34, 2003, p. 138.

29 ADORNO. 2003, p. 138.

30 BENJAMIN. 1994, p. 32.

31 BENJAMIN. O Surrealismo. O último instantâneo de inteligência europeia. In: Obras Escolhidas Vol. I:Magia e Técnica, Arte e Politica, São Paulo: Ed. Brasiliense, 1994, p. 33.
} 
certa objetivação nas ações que os surrealistas retratam em suas obras-de-arte e negando a vinculação desse movimento a interpretações psicológicas.

\section{O Processo de Desartização}

Em sua Teoria Estética, Adorno apresenta o conceito de desartização como um processo pelo qual a arte deixa de ser o que é e perde a sua especificidade. $A$ perda dessa especificidade, ele sublinha como "a perda de sua evidência" na sociedade. Adorno ainda assevera que "a arte não reage à perda da sua evidência apenas através de modificações concretas dos seus comportamentos, mas forçando a cadeia que é seu próprio conceito: o de que ela seja arte ${ }^{\prime 32}$. A tese sobre a perda de evidência da arte á salientada também logo no começo da obra:

Tornou-se manifesto que tudo o que diz respeito à arte deixou de ser evidente, tanto em si mesma como sua relação com o todo, e até mesmo o seu direito à existência. A perda do que se poderia fazer de modo não refletido ou sem problemas não é compensada pela infinidade manifesta do que se tornou possível e que se propõe à reflexão. $O$ alargamento das possibilidades revela-se em muitas dimensões como seu estreitamento. ${ }^{33}$

O fenômeno da desartização é primordialmente resultado da incompreensão das pessoas ${ }^{34}$ adestradas pela indústria cultural. Devemos entender que esta incompreensão das pessoas frente a algo que, como a arte, pode lhe causar estreitamento do seu significado, produz o fenômeno de que o indivíduo se vê frente a um enigma. Mas pelo estreitamento das sensações estéticas dos seus sentidos, ele não consegue decifrar ou mesmo admirar-se com tal obra. A incapacidade do público de entender ou fascinar-se por uma obra de arte é o estado cativo perpetrado pelos produtos mercantis.

Adorno escreve ainda sobre 0 fenômeno da desartização como incompreensão do público, ele frisa a insuficiência de poder mostrar a relevância da arte para aqueles que estão completamente imersos na cultura industrializada, porque eles já perderam a noção de uma expressão artística verdadeira, pois, agora a desartização da arte (Entkunstung der Kunst) prevalece em todos os domínios artísticos como o processo de descaracterização do que é a arte, o que nos faz pensar se a existência da arte ainda é possível hoje.

\footnotetext{
${ }^{32}$ Adorno, 2008, p 34.

33 ADORNO, Trad. Port. Artur Morão. Lisboa: Edições 70, 2008, p. 11.

34 Adorno chama esse fenômeno, que abarca não só a questão da incompreensão da arte, mas todo a cultura, de semicultura (Halbbildung).Para aprofundamento ver: ADORNO, Theodor W Teoria da Semicultura. Tradução de Newton Ramos-de-Oliveira, São Carlos: Editora UFSCar, 1992.
} 
Na verdade, o que desapareceu de fato foi à concepção de obras de arte, isto é, o modo de ver estético que tradicionalmente caracterizava a arte. É claro que Adorno entende que a arte sempre existiu por que nela havia a ideia de humanidade, mas o que hoje se vê, é uma humanidade que não progride, mas que, regride para uma possível era de extremos. Faz-se sentir a necessidade da arte expressar a intenção de sair das suas condições precárias. A arte tem seu lugar na sociedade como sua negação, sua antítese, porque a arte altera seu próprio conceito, contrapondo-se à sociedade, ao mesmo tempo em que, mantém um grau de heteronomia com ela.

Nesse aspecto, a arte é o não-idêntico ${ }^{35}$ quando se fala na autonomia da arte na Teoria Estética. O que a arte autônoma provoca na sociedade é o impacto de sua não identidade com ela. A arte aponta, nesse sentido, para uma verdade nãointencional, uma verdade não ditada pela coerência da consciência, o que a torna inalcançável pelo público do mundo administrado. Como exemplo deste não-idêntico que a arte tem, Adorno se refere a obra Guernica de Pablo Picasso:

\begin{abstract}
Que as obras recusem a comunicação é uma condição necessária, mas de modo algum a condição necessária da sua essência antideológica. $O$ critério central é a força da expressão. mediante cuja tensão as obras falam com um gesto sem palavras. Desvelam-se na expressão como estigma social; a expressão é o fermento social da sua forma autônoma. A principal testemunha a este propósito seria o quadro de Picasso Guernica que por uma rigorosa incompatibilidade como 0 realismo prescrito, adquire justamente, graças a uma construção inumana aquela expressão que causa o seu caráter de protesto, para lá de todo o mal-entendido contemplativo. ${ }^{36}$
\end{abstract}

A desartização da arte passa a ser uma escolha da própria arte de sua descaracterização consciente enquanto arte com o interesse de permanecer, e de existir, demarcando sua presença no mundo frente ao sistema ideológico dominante, redundando exatamente como uma ruptura das condições que a levaram quase a sua completa eliminação da vida humana. Adorno acrescenta ainda: Sob este

${ }^{35} \mathrm{O}$ conceito de não-identidade remonta a Dialética Negativa (1966). Nela, este conceito se contrapõe a identidade debatida por Platão a Hegel na história da filosofia. Na Dialética Negativa, o não-idêntico aparece como aquilo que a identidade do conceito não consegue dizer racionalmente através de categorias e sistemas. O papel do não-idêntico no âmbito da arte é justamente os elementos que a razão identificante não consegue conceituar, foge de suas possiblidades racionais. Ver: Adorno, Theodor W. Dialética Negativa. Trad. Br. Marco Antonio Casanova. Rio de Janeiro: Jorge Zahar Ed., 2009.

${ }^{36}$ ADORNO, Theodor W. Teoria Estética. Trad. Port. Artur Morão. Lisboa: Edições 70, 2008, p 358. 
aspecto. a Entkunstung da arte não se define apenas como fase da sua liquidação, mas como sua tendência evolutiva ${ }^{37}$.

A imanência da desartização da arte nos permite entender uma nova linguagem artística que a arte, sobretudo a arte moderna, incorpora, de elementos existentes no mundo administrado. Na medida que a obra de arte parece dizer mais do que ela é, ela possui uma transcendência que se torna possível em razão da coerência dos seus momentos. Adorno afirma ainda ao falar desta transcendência nas obras de arte:

Transcendência [nas obras de arte] é o seu discurso ou a sua escrita, mas uma escrita sem significação, ou, mais exatamente com uma significação truncada ou velada. (...) A arte degrada-se mais que o seu conceito quando não atinge essa transcendência. ${ }^{38}$

Revelado este elemento da transcendência na constituição de uma obra de arte, podemos entender que a arte se desartifica naquele momento prejudicial, quando comunga com os ditames da indústria cultural e da reprodutibilidade técnica, porém, no ato de resistir ao seu destino imposto como mercadoria. Tentando expressar algo que foge das construções pseudo-estéticas da cultura massificada, ela atinge o nível daquela transcendência, é o nível maior de sua presença.

Adorno elucida, para retomar essa ideia de transcendência, o tema da aura de Walter Benjamin, que aproxima transcendência e aura, tendo em vista a relação dialética de presença e ausência que caracteriza as duas na obra de arte, pois tanto em uma como na outra, manifesta-se a concepção nova a respeito da desratização, o que significa dizer que a desartização não tem o caráter prejudicial para a arte, mas, ao contrário, representa um caminho possível para a existência dela:

\footnotetext{
Benjamin chamou atenção para o fato de evolução inaugurada por Baudelaire interdizer a aura, aproximadamente como "atmosfera"; já em Baudelaire a transcendência da aparição artística é simultaneamente realizada e negada. Sob este aspecto, a Entkunstung da arte não se define apenas como fase da sua liquidação mas como sua tendência evolutiva. ${ }^{39}$
}

Adorno ainda vislumbra uma experiência estética do sujeito em relação a si mesmo que revela uma verdade por muitas vezes esquecida como ser vivente. Tal experiência estética é a sensação para aquilo que Adorno chama de abalo (Erschütterung). $\mathrm{O}$ abalo tem também o sentido de estremecimento, de comoção.

\footnotetext{
37 ADORNO, 2008, p. 126.

38 Idem. p. 125.

39 Ibidem, p. 125.
} 
Esses sentimentos são importantes elementos que diferenciam obras-de-arte e as simples mercadorias, pois, a sensação do abalo relembra ao individuo a sujeição a que ele esta submisso devido aos efeitos da indústria cultural.

O abalo é o momento em que o individuo abandona o estado de entorpecimento sustentado pela inércia da condição trivial de sua vivência cotidiana. A experiência da arte enquanto experiência da sua verdade ou inverdade é mais do que uma vivência subjetiva: é a irrupção da objetividade na consciência subjetiva ${ }^{40}$. O individuo perde o chão sob seus pés e a possiblidade da verdade que se vê no objeto de arte torna-se palpável.

Sob este aspecto, Adorno apresenta uma passagem onde é interessante observar que o abalo chega a ter uma semelhança com a concepção de Kant do conceito de sublime, e que a conexão entre o abalo e a desartização acontece quando essa última aparece como fundamento interior através do qual aquele se concretiza:

O abalo intenso, brutalmente contraposto ao conceitual usual de vivência,
não é uma satisfação particular do eu, e é diferente do prazer. E antes um
momento de liquidação do eu que, enquanto abalado, percebe os próprios
limites e finitude. Esta experiência é contrária ao enfraquecimento do eu,
que a indústria cultural promove. A ideia de um abalo profundo seria para
ela uma loucura vã, eis a motivação mais intima da Entkunstung da arte. A
fim de olhar apenas um pouquinho para lá da prisão, que ele próprio é, o eu
precisa, não da dispersão, mas da mais extrema tensão; isso preserva o
abalo profundo de resto um comportamento involuntário, da regressão. Na
estética do sublime, Kant representou fielmente a força do sujeito como a
sua condição. ${ }^{41}$

O abalo exige que o sujeito seja capaz de se colocar no mais alto de si mesmo o que realmente explicaria o fato de muitos evitarem o sublime, devido à incapacidade de tal esforço de grandeza da alma.

\section{Considerações Finais}

É inegável a força do debate convergente de Benjamin e Adorno. Dois pensamentos que se cruzam e entrelaçam, mas que não tem a mesma direção. Dessa separação de pensamentos, podemos perguntar qual dos dois esteve mais perto do que o futuro para eles em seu tempo confirmaria? Se olharmos na história do século XX, é Adorno o mais assertivo.

\footnotetext{
${ }^{40}$ Adorno. 2008, p. 368.

${ }^{41}$ Ibidem, p. 369.
} 
$\mathrm{Na}$ Alemanha, antes que os aliados vencessem a Segunda Guerra, os nazistas promoviam um extermínio em massa a judeus, duas bombas atômicas foram lançadas no Japão (já derrotado) por autoria dos Estados Unidos, e o fracasso do socialismo nas mãos de Stalin na URSS só confirmam o negativismo adorniano. Tratava-se de um irracionalismo que promovia a barbárie, a perseguição ao judeus e as minorias no mundo. A intrigante frase "não há poesia depois de Auschwitz" ${ }^{\text {"2 }}$ é uma máxima na qual Adorno vê a humanidade sem motivo para ainda sonhar.

Em Benjamin há uma certa atração pelo novo que a tecnologia estava proporcionando, e por algo que os futuristas ${ }^{43} \mathrm{com}$ seu olhar artístico expressavam em suas obras ao enaltecer às maquinas. Porém, o tempo decorrente simplesmente confirmaria que o fascínio pelas máquinas poderia dar errado, quando elas estiveram presentes em dois grandes eventos bélicos avassaladores na primeira metade do século XX.

Mesmo com todo esse descaminho que os filósofos expõem em seus pensamentos sobre a arte, eles nos promovem a acompanhá-los nesse debate, a termos um entendimento de nosso tempo com um pensamento que se recusa a aceitar passivamente o que é posto e responder com uma negatividade como fez Adorno e também cultivar em nossa vontade a terna esperança que Benjamin sempre mantinha.

\footnotetext{
${ }^{42} \mathrm{O}$ problema referente à poesia após Auschwitz consiste numa aporia inevitável para uma reflexão sobre estética e ética em Adorno, a frase aparece pela primeira vez no ensaio "Crítica cultural e sociedade" que explicita a impossibilidade que permeia a poesia que se articula com o real dos campos de concentração. Para aprofundamento ver: ADORNO, Theodor W. Crítica Cultural e sociedade. In: Prismas: crítica cultural e sociedade. Trad. bras. Augustin Wernet e Jorge Mattos Brito de Almeida. São Paulo: Ática, 1998, p. 7 - 26.

${ }^{43}$ MARINETTI. O Futurismo. Lisboa: Hiena, 1995.
} 


\section{REFERÊNCIA}

ADORNO, Theodor W. Teoria Estética. Trad. port. Artur Morão. Lisboa: Edições 70, 2008.

Dialética Negativa. Trad. bras. Marco Antonio Casanova. Rio de Janeiro: Jorge Zahar Ed., 2009.

; Horkheimer, Max. Dialética do Esclarecimento: fragmentos filosóficos. Trad. bras. Guido Antonio de Almeida. Rio de Janeiro: Jorge Zahar Ed., 2006.

34,2003

Revendo o Surrealismo. In: Notas de literatura I, São Paulo: Editora

Teoria da Semicultura. Tradução de Newton Ramos-de-Oliveira, São Carlos: Editora UFSCar, 1992.

Ática, 1994, p. 92 - 99.

Tempo Livre. In: Indústria Cultural e Sociedade. Seleção de textos de Jorge Mattos Brito de Almeida Trad. Br. de Juba Elisabeth Levy. São Paulo: Paz e Terra, 2009, p. 62 -70.

BENJAMIN, Walter. A obra de arte na era de sua reprodutibilidade técnica. In: Obras Escolhidas. Magia e Técnica, Arte e Politíca. Trad. Br. Sérgio. P. Rouanet. São Paulo: Brasiliense, 1994.

O Surrealismo. 0 último instantâneo de inteligência europeia. In: Obras Escolhidas Vol. I: Magia e Técnica, Arte e Politica, São Paulo: Ed. Brasiliense, 1994

FREITAG, Barbara. Teoria Crítica: Ontem e Hoje. São Paulo: Editora Brasiliense, 1986.

KOTHE, Flávio R. Benjamin e Adorno: confrontos. São Paulo: Ática, 1978.

MARINETTI, F.T. O Futurismo. Lisboa: Hiena, 1995.

PALHARES,Taísa Helena Pascale. Aura: a crise da arte em Walter Benjamin. São Paulo: Barracuda, 2006.

ROSEN, Michael. Benjamin, Adorno e o acaso da aura, p. 67 - 84. In: RUSH, Fred (Org). Teoria Crítica. Trad. Br. Beatriz Katinsk, Regina Andrés Rebollo. Aparecida: Ideias \& Letras, 2008. 